COVER ESSAY

\title{
Sweet and spicy flavours: new brands for minorities and youth
}

G N Connolly

Tobacco Control 2004;13:211-212. doi: 10.1136/tc.2004.009191

\begin{abstract}
The tobacco industry is now adding sweet and spicy flavours to its products in order to increase sales to youth and minorities
\end{abstract}

Correspondence to: Dr Gregory N Connolly, Harvard School of Public Health, Boston,

Massachusetts, USA; gconnoll@hsph.harvard. edu
$\mathrm{T}$ he cover of this issue of Tobacco Control exposes a new tobacco industry practice of lacing cigarette brands popular with youth and minorities with sweet and spicy flavours. This is a new phenomenon for cigarette manufacturers but is reminiscent of an old practice. A hundred years ago, the rotten meat of dead horses was made more palatable for human consumption by adding ingredients that masked the meat's toxicity. It was called adulteration. shut down this deadly practice when Congress passed the FDA law in 1906. Yet, a few years ago, the US Supreme Court gave cigarette companies carte blanche approval to use sweeteners to adulterate cigarettes when it struck down the FDA rule asserting jurisdiction over tobacco products. The cover picture shows how an unregulated industry can turn a blowtorch into rice pudding by adding spoonfuls of sugar to help its toxic "medicine" go down.

\section{TARGETING YOUTH}

The tobacco industry argues that they "changed" after signing the Master Settlement Agreement (MSA) in 1998 with the states' attorneys general. They agreed not to directly or indirectly target youth with their advertising. Before the ink was dry on the MSA, the companies launched their own corporate advertising campaigns claiming how much they had changed. The ads stated that the companies didn't want kids to smoke and adults should make an informed choice about an addictive practice. But have they really changed? Massachusetts banned cigarette advertising within 1000 feet $(300 \mathrm{~m})$ of schools and playgrounds a few months after the MSA, only to be sued by the four major tobacco companies. Massachusetts lost that case when the same five US Supreme Court judges who voted down FDA regulation, ruled that Marlboro and Camel advertisements could be adjacent to children's swing-sets in the state. ${ }^{1}$

Massachusetts was also sued when they passed a law requiring tobacco companies to tell consumers what they put in cigarettes. Last year the federal Appellate Court upheld a lower court ruling declaring the ingredient disclosure provision of the Act unconstitutional. ${ }^{2}$ The tobacco industry spent millions of dollars in legal fees to The US Food and Drug Administration (FDA) prevent Massachusetts from helping them to "truly" change. The disclosure ruling was a success for big tobacco, a defeat for smokers who wished to know about what was actually in the products they were buying, and a defeat for public health.

In 1999, Philip Morris (PM) ran newspaper advertisements, touting the end of billboard advertising as required by the MSA. The ads claimed that they were doing this to protect kids. What the PM ads didn't tell you is that they only recycled billboard advertising expenditures into magazines, many read by youth, and into promotional gimmicks. It took a successful California lawsuit against RJ Reynolds (RJR) to end the hypocritical practice of advertising in youth magazines. However, after losing the case, RJR simply transformed the packs of its flavoured Salem brand into a mega advertisement. The MSA banned promotional items, but the new Salem package is a promotional silver tin. The pack contains a coupon for a free, future purchase and another insert that resembles a Pokemon card popular with pre-teens. The card has a 1-800 number and website address. Despite the MSA, RJR has all the advertising it needs, from the pack to the web, to recruit new smokers for the 21 st century.

\section{WHY HAVEN'T THE COMPANIES CHANGED?}

After the MSA, RJR lost large market share to PM. Sales for RJR's flagship Camel brand fell $15 \%$ from 1998 to $2001 .^{3}$ PM's Marlboro was $^{\prime}$ down only $3 \%$ during the same period. In 2002, RJR retooled the filter of Camel with a blue plastic "flavour" pellet (fig 1). The polyethylene capsule allowed RJR to create nifty niche brands called Camel "Exotic Flavors" and the gimmick worked. Camel sales rose $4 \%$ in 2002 while Marlboro fell $6 \%$. This year looks even better. This summer RJR is asking all of us to take a Camel "Koula Kolada" or "Twista Lime" to smoke at the beach. The possibilities open to tobacco companies by lack of regulation are extraordinary. If the current generation of candy flavours don't lift sales, all sorts of possibilities lie in today's vast pharmacopoeias.

Using candy flavours in cigarettes is like adding a sachet of sugar to a side of rancid meat. The FDA can forbid sweeteners for masking the taste of rotten meat but not the "Berry Bayou Blast" or "Crema Mint" in Camels. The

Abbreviations: B\&W, Brown and Williamson; FDA, Food and Drug Administration; MSA, Master Settlement Agreement; PM, Philip Morris; RJR, RJ Reynolds 
Blue plastic-like cylinder embedded in filter (non-smoked)

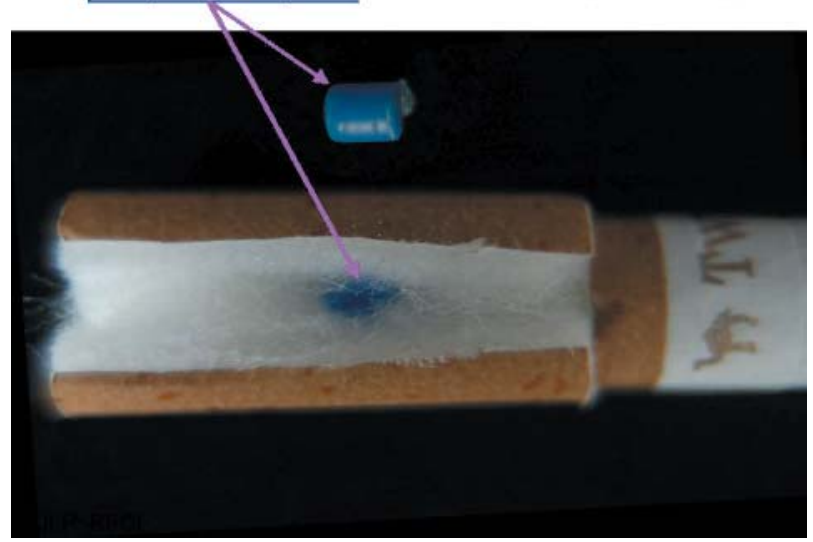

Figure 1 "Twist"-Camel "Exotic Flavors". R J Reynolds Tobacco Company. Photo by Dr John Pauly, Roswell Park Cancer Institute.

financial rewards of candy laden filters could be great for RJR. Not surprisingly, Brown and Williamson (B\&W) also sees sweet bucks in the numbers and launched their own confectionary cigarettes in 2004 with Kool Smooth Fusion flavours including "Mintrique", "Midnight Berry", and "Moocha Taboo". Hip-Hop brands with popular disc jockeys emblazoned on the packs of "Kool Menthol Caribbean Chill" are used to entice minorities. Not to be outdone by B\&W in the minority market, RJR recently spiced up its Salem menthol packs, with "Cool Myst", "Fire and Ice", and "Dark Currents" flavours. PM is also going after minorities while keeping well below the radar screen of tobacco control activists. In February 2004, PM introduced their new Marlboro Menthol Shorts, a $70 \mathrm{~mm}$ discount brand exquisitely designed for the African American lung. Why should we be surprised? Isn't menthol the ultimate tobacco flavour?

Maybe the MSA has backfired and its limited advertising restrictions and price increases have only forced the tobacco industry to adapt. Since the MSA was signed the companies have not changed, they have only become smarter and more competitive for the lungs of youth and minorities. Tobacco control advocates may have changed too. Today, are we less vigilant and more indifferent to the reckless, irresponsible practices of big tobacco? Are we more complacent today than we were when the MSA was signed? It's time to re-engage the tobacco industry and fight for the health of our children and the disadvantaged. It's time we made smoking history.

The cover of this issue was designed by Anthony Brown at Roswell Park Cancer Institute

\section{REFERENCES}

1 Supreme Court of the United States. Lorillard Tobacco Co. et al, Petitioners, v. Thomas F. Reilly, Attorney General of Massachusetts et al. Nos. 00-596-00$597,6 / 28 /, 2001$

2 United States Court of Appeals, First Circuit. Philip Morris, Incorporated, et al, Plaintiffs, Appellers v. Scott Harshbarger, Attorney of Massachusetts, et al, Defendant, Nos. 98-1199; 98-, 1200.

3 Maxwell J. The Maxwell report 2002. Richmond, Virginia: Wheat First Securities, 2003.

\section{The lighter side}

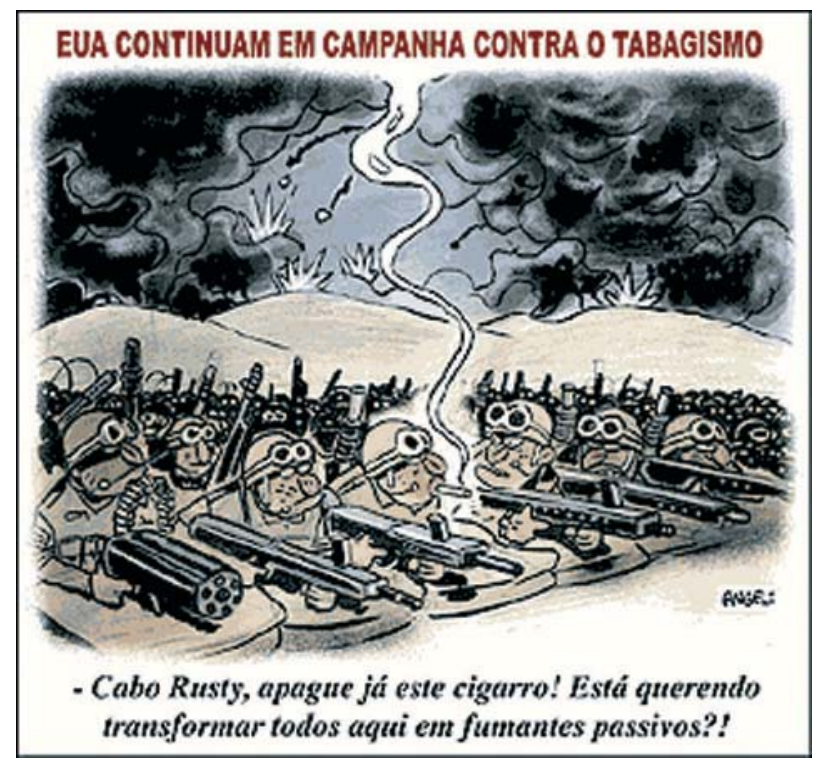

CFolha de S.Paulo. The US keeps up its anti-tobacco campaign "Cpl. Rusty, put out that cigarette already! Do you want to turn us all into passive smokers?!" 